\title{
Endoscopic injection of adrenaline for actively bleeding ulcers: a randomised trial
}

\author{
S C S CHUNG, J W C LEUNG, R J C STEELE, T J CROFTS, A K C LI
}

\begin{abstract}
A prospective randomised trial was performed to assess the efficacy of endoscopic injection of adrenaline for actively bleeding ulcers. Emergency endoscopy in 961 patients admitted for upper gastrointestinal haemorrhage identified 68 patients with actively bleeding ulcers. These 68 patients were randomised to receive either endoscopic injection of adrenaline or no endoscopic treatment. After endoscopy both groups were managed in an identical manner, and strict criteria for emergency operation were adhered to in both groups. Bleeding was initially controlled in all 34 patients assigned to the treatment group. Significantly fewer patients in the treatment group than in the control group needed emergency operations (five $v 14$, respectively). In addition, in the treatment group the median transfusion requirement was significantly less (three $v$ five units of blood) and the median hospital stay shorter (six $v$ eight days). No complications were observed with the injection of adrenaline, and the rate of healing of ulcers in those attending for endoscopy six weeks after discharge was similar in both groups $(81 \%$ (17 out of 21 patients) in the treatment group $v 79 \%$ (11 out of 14$)$ in the control group).
\end{abstract}

Injection of adrenaline is effective in stopping bleeding from actively bleeding ulcers.

\section{Introduction}

Injection treatment has been used extensively to stop bleeding from haemorrhoids and oesophageal varices but the use of local injections for bleeding ulcers has received scant attention until recently.

\footnotetext{
Combined Endoscopy Unit, Prince of Wales Hospital, Chinese University of Hong Kong, Shatin, Hong Kong

S C S CHUNG, FRCSED, MRCP, lecturer in surgery

J W C LEUNG, MD, MRCP, senior lecturer in medicine

R J C STEELE, MD, FRCSED, visiting lecturer in surgery

T J CROFTS, MS, FRCS, senior lecturer in surgery

A K C LI, MD, FRCS, professor of surgery

Correspondence to: $\mathrm{Mr}$ Chung.
}

Success rates of $80-100 \%$ have been reported with alcohol, ${ }^{12}$ laureth 9 (polidocanol), ${ }^{3}$ hypertonic saline mixed with adrenaline, ${ }^{4}$ and adrenaline followed by laureth $9 .{ }^{56} \mathrm{We}$ previously reported the use of adrenaline (diluted 1/10000) in actively bleeding ulcers in 37 patients. Initially, success was achieved in all patients, but in five patients the ulcer rebled and three of them needed emergency operations. $^{?}$

The results of these uncontrolled studies are impressive, but bleeding from a peptic ulcer stops spontaneously in over $80 \%$ of patients. ${ }^{8}$ Thus any technique of haemostasis must be validated in a randomised controlled study before it can be declared clinically useful. We report such a prospective randomised trial of the endoscopic injection of adrenaline in treating actively bleeding ulcers.

\section{Patients and methods}

Emergency endoscopy - All patients admitted to this hospital with upper gastrointestinal haemorrhage had endoscopy within 24 hours after admission. Patients who were in shock or bleeding massively had endoscopy as soon as they had been resuscitated. When blood clots in the stomach obscured the view stomach lavage was carried out with an overtube system. Blood clots and coffee grounds covering the base of ulcers were washed away by a modified water pump. ${ }^{10}$

Inclusion criteria and randomisation-All patients with actively bleeding ulcers were included. Patients excluded were those with bleeding only on contact with the endoscope, those whose visible blood vessels were not bleeding, those with blood clots covering the base of an ulcer that was not actively bleeding, and those who showed no signs of recent haemorrhage on endoscopy. Patients were randomised into control and treatment groups at endoscopy, when a sealed numbered envelope containing the treatment option, which was determined by a list of random numbers generated by a computer, was opened. Bleeding from ulcers was categorised as pulsatile (arterial spurting) or oozing (non-pulsatile bleeding that persisted after washing).

Injection-The technique of endoscopic injection of adrenaline has been described. ${ }^{7}$ With a flexible needle injector (Olympus NM-1K) inserted through the biopsy channel of the endoscope $0.5 \mathrm{ml}$ aliquots of adrenaline ( $1 /$ 10000 dilution) were injected by multiple punctures into and around the bleeding point until all bleeding stopped.

Follow up-After endoscopy all patients were returned to the surgical gastroenterology ward for observation and given $\mathrm{H}_{2}$ antagonists (cimetidine $200 \mathrm{mg}$ or ranitidine $50 \mathrm{mg}$ every six hours). Blood pressure and pulse were monitored hourly. Central venous pressure was monitored in patients over 
60 years of age, in those with cardiac disease, and in those who had had a massive bleed. Haemoglobin concentration was measured daily, and, if necessary, blood transfusions were given to maintain haemoglobin concentrations above $100 \mathrm{~g} / \mathrm{l}$. Endoscopy was repeated 24 hours later. Repeat injections of adrenaline were given to patients in the treatment group if active bleeding was seen.

Emergency operations-The need for emergency operation was determined by two experienced surgeons, one of whom did not give the injection treatments. Identical criteria for emergency surgery were strictly adhered to for both the treatment and the control groups. Emergency operations were performed if any one of three conditions was satisfied: $(a)$ failure of blood pressure or pulse rate to stabilise after four units of blood, $(b)$ a total transfusion of more than eight units of blood, or $(c)$ a rebleed as shown by haematemesis or red aspirate from the nasogastric tube associated with tachycardia or hypotension, or both.

Trial indices - The treatment and control groups were compared for transfusion requirements, emergency surgery, stay in hospital, and mortality in hospital. Statistical evaluation was carried out with the $\chi^{2}$ and median tests.

\section{Results}

From November 1985 to December 1986961 patients had emergency endoscopy for acute gastrointestinal haemorrhage. Altogether 68 patients with actively bleeding ulcers were identified and entered into the study. Two patients who were actively bleeding at the time of endoscopy were not included because the bleeding lesion could not be seen. One of them was found to have an aorto-oesophageal fistula at autopsy, the other was found to be bleeding from a gastric varix at operation. Table I shows the clinical details of patients randomised to the treatment and control groups. The two groups were comparable in age, sex, site of ulcer, and severity of bleeding.

TABLE I-Details of patients entered into study

\begin{tabular}{lcc}
\hline & $\begin{array}{c}\text { Treatment } \\
\text { group } \\
(\mathrm{n}=34)\end{array}$ & $\begin{array}{c}\text { Control } \\
\text { group } \\
(\mathrm{n}=34)\end{array}$ \\
\hline No of men & 26 & 26 \\
No of women & 8 & 8 \\
Mean (SD) age (years) & $51(19)$ & $54(22)$ \\
No with gastric ulcer & 10 & 12 \\
No with duodenal ulcer & 24 & 22 \\
No with haemoglobin $<100 \mathrm{~g} / 1$ & 19 & 23 \\
No in shock & 11 & 11 \\
No with spurting ulcer & 9 & 10 \\
No with oozing ulcer & 25 & 24 \\
\hline
\end{tabular}

Table II summarises the results of the endoscopic injection of adrenaline. Adrenaline controlled bleeding in all 34 patients in the treatment group. The volume of adrenaline used ranged from $3-14 \mathrm{ml}$ (mean $6.8 \mathrm{ml}$ ), and no complications were observed. Two patients rebled and were operated on six and 16 hours after injection. At repeat endoscopy 24 hours later ulcers in six of the 32 remaining patients were found to be bleeding again (one spurting, five oozing), but repeat injections controlled the bleeding in all six patients. Three of the 32 patients required emergency surgery at 34, 48, and 48 hours after the initial injection. None of the 29 patients who had no active bleeding at repeat endoscopy 24 hours after the initial injection required emergency operation. In the five patients who required emergency operation the indications were haemodynamic instability after four units of blood had been transfused in one patient, transfusion of eight or more units of blood in two others, and rebleeding in the remaining two; three patients satisfied more than one criterion. The blood transfusion requirement ranged from 0-12 units (median three units, interquartile range three units).

In the control group 14 patients had emergency operations. Four had operations within six hours after endoscopy, four between six and 25 hours, two after one day, three between three and five days, and one at 10 days after endoscopy. Seven of them had operations because of haemodynamic instability after four units of blood were transfused, eight because more than eight units had been transfused, and four because of rebleeding of the ulcer; four patients satisfied more than one criterion. The blood transfusion requirement ranged from $0-25$ units (median five units, interquartile range five units).

Elective operations - Two patients in each group who had had multiple episodes of bleeding underwent elective ulcer operations 7-10 days after their first endoscopy. None had shown any evidence of rebleeding before operation.

Mortality-Three patients in the treatment group died in hospital, one of heart failure on day 1 , one of postoperative pneumonia on day 5 , and one of renal failure on day 23. Two patients died in the control group, one of pneumonia on day 5 and the other of hepatorenal failure on day 30 .

Healing of ulcers - Excluding the five patients who died and the 21 who had had operations, 42 patients were discharged from hospital taking $\mathrm{H}_{2}$ antagonists. Seven patients did not return for follow up, but $35(83 \%)$ returned for endoscopy six weeks after discharge. Ulcers were completely healed in 17 of the 21 patients $(81 \%)$ in the treatment group and in 11 of the $14(79 \%)$ patients in the control group.

\section{Discussion}

Despite advances in diagnosis and management the hospital mortality of upper gastrointestinal haemorrhage has remained constant at around $10 \% .{ }^{11-13}$ This may partly be explained by the increase in the proportion of elderly patients. ${ }^{14}$ Continued bleeding or rebleeding of ulcers in hospital is associated with a sixfold to 12-fold increase in mortality. "is To avoid such rebleeding early operations have been advocated for subgroups of patients selected on clinical and endoscopic grounds. ${ }^{16}{ }^{17}$ In an increasingly elderly population of patients an aggressive surgical policy may merely exchange "medical" for postoperative deaths, with no effect on overall mortality. ${ }^{18}$

Although emergency endoscopy has not been shown to reduce the mortality of gastrointestinal haemorrhage in randomised trials, endoscopy has become the investigation of choice in most hospitals for patients admitted with gastrointestinal bleeding. With the accurate identification of the bleeding point, haemostasis by endoscopy, which avoids the risks of general anaesthesia and operation, is clearly very attractive. Endoscopic laser photocoagulation has attracted much attention both in the lay press and in medical publications. The equipment is expensive, and difficult to use, and controlled trials have given contradictory results. ${ }^{2021}$ Newer thermal methods, such as bipolar electrocoagulation ${ }^{22}$ and heat probes, ${ }^{23}$ allow pressure to be applied to the bleeding point during coagulation to produce a better seal. Early results are promising, but further assessment is necessary.

Most patients presenting with upper gastrointestinal bleeding are admitted to district general hospitals. Those whose ulcers continue to bleed are unlikely to be fit for transfer to a specialised unit. To lower the mortality associated with bleeding peptic ulcers an endoscopic procedure should be readily available in most hospitals and be technically easy to perform. Endoscopic injections require no specialised equipment, and the technique is comparatively easy to master. The successful use of injection treatment for non-variceal bleeding has been reported by several groups. Although the results with sclerosants in uncontrolled clinical studies are impressive, the ulcerogenic potential of these substances is worrying; ulcers have been shown to grow bigger and healing to be retarded with large

TABLE II-Results of endoscopic injection of adrenaline by group and type of bleeding from ulcer

\begin{tabular}{|c|c|c|c|c|c|c|c|}
\hline & \multicolumn{3}{|c|}{ Treatment group } & \multicolumn{3}{|c|}{ Control group } & \multirow[b]{2}{*}{$\begin{array}{l}\text { Significance } \\
\text { (p value) }\end{array}$} \\
\hline & $\begin{array}{l}\text { Spurting ulcer } \\
\quad(\mathrm{n}=9)\end{array}$ & $\begin{array}{l}\text { Oozing ulcer } \\
\quad(n=25)\end{array}$ & $\begin{array}{c}\text { Total } \\
(n=34)\end{array}$ & $\begin{array}{l}\text { Spurting ulcer } \\
(\mathrm{n}=10)\end{array}$ & $\begin{array}{l}\text { Oozing ulcer } \\
(n=24)\end{array}$ & $\begin{array}{c}\text { Total } \\
(\mathbf{n}=34)\end{array}$ & \\
\hline $\begin{array}{l}\text { Median No (range) of units of blood transfused } \\
\text { No having emergency operation } \\
\text { Median (range) stay in hospital (days) } \\
\text { No of deaths }\end{array}$ & $\begin{array}{c}4(1-8) \\
3 \\
6(3-13)\end{array}$ & $\begin{array}{c}3(0-12) \\
2 \\
5(2-27) \\
3\end{array}$ & $\begin{array}{c}3(0-12) \\
5 \\
6(2-27) \\
3\end{array}$ & $\begin{array}{c}6(3-10) \\
7 \\
8.5(4-18)\end{array}$ & $\begin{array}{c}4(0-25) \\
7 \\
8(3-108) \\
2\end{array}$ & $\begin{array}{c}5(0-25) \\
14 \\
8(3-108) \\
2\end{array}$ & $\begin{array}{l}<0.05 \\
<0.02 \\
<0.005 \\
\quad \text { NS }\end{array}$ \\
\hline
\end{tabular}


volumes of laureth $9,{ }^{3}$ and in another study one patient died of a perforated ulcer when alcohol was used. ${ }^{1}$

In clinical trials on gastrointestinal bleeding various end points can be used to determine the success or otherwise of treatment. ${ }^{24}$ The most unequivocal end point is death. With modern management in a specialised unit the mortality from bleeding ulcers is under $10 \%$. In most patients the cause of death is a coexisting irreversible medical condition rather than bleeding. In our study five out of 68 patients died, giving a mortality of $7 \%$. It is unlikely that a difference in mortality can be shown in a trial of reasonable size. Other end points include rates of rebleeding, transfusion requirements, need for emergency operation, and length of stay in hospital. Rebleeding may be difficult to define clinically as it is difficult to distinguish from continued bleeding. Although haematemesis associated with hypovolaemic shock leaves no doubt that active bleeding has occurred, diagnosing a smaller rebleed may be equivocal. Melaena may be passed days after the bleeding episode. A fall in haemoglobin concentration may be due to haemodilution. Transfusion requirements and emergency operations are also determinants that are influenced by clinical judgment, and the time spent in hospital may be affected by unrelated social factors.

Our trial was not conducted blind. To avoid bias and difficulties in interpretation unequivocal criteria for transfusion and operation were drawn up and strictly adhered to. Rebleeding was not one of the end points because it is difficult to diagnose. Instead, unequivocal rebleeding (haematemesis and shock) was included as one of the criteria for emergency operation.

The results of our randomised controlled study confirm our earlier experience that injection of adrenaline is effective and safe.? Initial haemostasis was achieved in all 34 patients in the treatment group. No complications were observed; ulcers did not extend on repeat endoscopy at 24 hours and the rates of healing in the control and treatment groups were identical. The treatment group required significantly less blood, needed fewer emergency operations, and had a shorter stay in hospital than the control group.

The mechanism by which injection treatment stops bleeding is conjectural. The effect of the volume of injected material may be important. ${ }^{25}$ We showed that submucosal injection of adrenaline reduced the rate of bleeding from experimental gastric ulcers in dogs, whereas the inert carrier substance had no effect. ${ }^{26}$ The pharmacological action of adrenaline is probably important in promoting haemostasis.

We did not find any local or systemic complication attributable to the injection of adrenaline either in the present trial or in our earlier pilot study. Catecholamines have a significant first pass extraction by the liver. ${ }^{27}$ Submucosal injection of adrenaline into the stomach or the duodenum is less likely to cause cardiovascular side effects than systemically injected adrenaline. Tissue necrosis from local ischaemia remains a theoretical risk, but we did not observe any extension of the ulcer on repeat endoscopy or any delay in the healing of ulcers in our patients. There are no data on the maximum safe dose. As a general rule we recommend a maximum dose of up to $10 \mathrm{ml}$. In one of our patients $14 \mathrm{ml}$ was injected with no untoward effect.

Data on the natural course of an actively bleeding ulcer are scanty because most patients with active bleeding either have endoscopic haemostasis or are referred for emergency operation. Scrutiny of our control group throws some light on the natural course of actively bleeding lesions seen at endoscopy. In our control group of 34 patients with active bleeding, $41 \%$ ( $70 \%$ of patients with spurting vessels and $29 \%$ of those with oozing ulcers) required emergency operation. Although active bleeding seen at endoscopy does not mandate immediate surgery, it does identify a group at high risk in whom future studies on endoscopic haemostasis should be concentrated.

We thank Dr Y M Lam for statistical advice.

\section{References}

1 Asaki S, Nishimura T, Satoh A, et al. Endoscopic control of gastrointestinal haemorrhage by loca injection of absolute alcohol: a clinical study. Tohoku f Exp Med 1983;141:373-83.

2 Sugawa C, Fugita Y, Ikeda T, Walt AJ. Endoscopic hemostasis of bleeding of the upper gastrointestinal tract by local injection of ninety-eight per cent dehydrated ethanol. Surg Gynecol Obstet 1986;162:161-3.

3 Wordehoff D, Gros $\mathrm{H}$. Endoscopic haemostasis by injection-therapy in high risk patients. Endoscopy 1982;14:196-9.

4 Hirao M, Kobayashi T, Masuda K, et al. Endoscopic local injection of hypertonic salineepinephrine solution to arrest hemorrhage from upper gastrointestinal tract. Gastrointest Endosc 1985;31:311-7.

5 Soehendra N, Grimm H, Stenzel M. Injection of non-variceal bleeding lesions of the gastrointestinal tract. Endoscopy 1985;17:129-32.

6 Kortan P, Haber G, Maron N. Endoscopic injection therapy for non-variceal bleeding lesions of the upper gastrointestinal tract. Gastrointest Endosc 1986;32:145-6.

7 Leung JWC, Chung SCS. Endoscopic injection of adrenalin in bleeding peptic ulcer. Gastrointes Endosc 1987;33:73-5.

8 Northfield TC. Factors predisposing to recurrent haemorrhage after acute gastrointestinal bleeding. BrMed f 1971;i:26-8.

9 Cotton PB. Overtube (sleeves) for upper gastrointestinal endoscopy. Gut 1983;24:863-6.

10 Chung SCS, Leung JWC. Improving the view at emergency endoscopy. Endoscopy 1987;19:47.

11 Schriller KFR, Truelove SC, Gwyn Williams D. Haematemesis and melaena, with special reference to factors influencing the outcome. BrMed f 1970;ii:7-14.

12 Silverstein FE, Gilbert DA, Tedesco FJ, et al. The national ASGE survey on gastrointestinal bleeding. II. Clinical prognostic factors. Gastrointest Endosc 1981;27:80-93.

13 Morgan AG, Clamp SE. OMGE International Upper Gastro-intestinal Bleeding Survey 1978-1982. Scand F Gastroenterol [Suppl] 1984;95:41-58.

14 Kang JY, Piper DW. Improvement in mortality rates in bleeding peptic ulcer. Med J Aust 1980;1:213-5.

15 Avary-Jones F. Hematemesis and melena. Gastroenterology 1956;30:166

6 Morris DL, Hawker PC, Brearley S, Simms M, Dykes PW, Keighley MRB. Optimal timing of operation for bleeding peptic ulcer: prospective randomised trial. Br Med J 1984;288:1277-80.

17 Brearley S, Morris DL, Hawker PC, Dykes PW, Keighley MBR. Prediction of mortality at endoscopy in bleeding peptic ulcer disease. Endoscopy 1985;17:173-4

18 Bornman DC, Theodorou NA, Shuttleworth RD, Essel HP, Markes IN. Importance of hypovolaemic shock and endoscopic signs in predicting recurrent haemorrhage from peptic ulceration: a prospective evaluation. Br Med f 1985;291:245-7.

19 Vellacott KD, Dronfield MW, Atkinson M, Langman MJS. Comparison of surgical and medical management of bleeding peptic ulcers. Br Med $\mathcal{J}$ 1982;284:548-50.

20 Ihre T, Johansson C, Seligson U, et al. Endoscopic YAG laser treatment in massive upper gastrointestinal bleeding. Scand f Gastroenterol 1981;16:633-40.

21 Macleod IA, Mills PR, Mackenzie JF, Joffe SN, Russell RI, Carter CD. Neodymium yttrium aluminium garnet laser photocoagulation for major haemorrhage from peptic ulcers and single aluminium garnet laser photocoagulation for major haemorrhage f

22 Laine L. A controlled trial of multipolar electrocoagulation in the treatment of upper gastrointestinal hemorrhage. Gastroenterology 1986;90:1508.

23 Johnston JH, Sones JQ, Long BW, Posey EL. Comparison of heater probe and YAG laser in endoscopic treatment of major bleeding from peptic ulcers. Gastrointest Endosc 1985;31:175-80.

24 Langman MJS. Upper gastrointestinal bleeding: the trial of trials. Gut 1985;26:217-20.

25 Rutgeerts P, Gebos K, Vantrappen G. Tissue damage produced by hemostatic injections. Gastrointest Endosc 1986;32:179.

26 Chung SCS, Leung JWC, Galvina M, Lee TW. The effect of submucosal adrenaline on blood loss from standard bleeding ulcers. Gut 1987;128:A1402.

27 LeVeen HH, Diaz C, Falk C, et al. A proposed method to interrupt gastrointestinal bleeding: preliminary report. Ann Surg 1972;175:459-69.

(Accepted 2 February 1988) 